\title{
A PARTICIPAÇÃO DA FAMÍLIA NA PERSPECTIVA DA VIVÊNCIA DA DOR DE PARTO ${ }^{1}$ PARTICIPATION OF THESE WOMEN'S RELATIVES IN THEIR EXPECTATION

\author{
LA PARTICIPACIÓN DE LA FAMILIA EM LA PERSPECTIVA \\ DE LA VIVENCIA DEL DOLOR DE PARTO
}

Emília Saito*

Dulce Maria Rosa Gualda**

\begin{abstract}
RESUMO: Este estudo etnográfico buscou compreender a vivência da dor de parto de mulheres que deram à luz em um hospital-escola da cidade de São Paulo, onde o emprego da analgesia não é realizada com freqüência e a presença do acompanhante no parto também é restrita, adotando a Antropologia Cultural como referencial. A dor de parto, apesar de ser um evento característico do parto, neste estudo evidenciou-se como uma preocupação da mulher com esta futura, mas próxima experiência, durante a gestação. A assistência pré-natal proporcionada tem se mostrado falha quanto a este aspecto, o que salienta a importância dos familiares destas mulheres em compartilharem desta expectativa.
\end{abstract}

PALAVRAS-CHAVE: Dor; Parto; Família.

\section{INTRODUÇÃO}

A dor é um fenômeno universal e presente no nosso cotidiano. S egundo Ferreira (1994), a presença da sensação dolorosa é, ainda, a causa apontada com maior freqüência pelas pessoas como a motivação da busca de assistência médica por ser percebida por estas como indicativo de um processo patológico. 0 autor enfatiza ainda que a relação existente entre a experiência da dor e o reconhecimento entre um estado mórbido é evidenciado pela própria raiz etimológica comum do latim das palavras dor e doença. A dor é percebida como um sintoma, portanto, um fenômeno único e exclusivo do paciente e confere em caráter invisível à doença.

Na situação de nascimento e parto, a contração uterina - conhecida popularmente como dor de parto - é um componente biológico e fisiológico do processo de parturição. Assim, os profissionais de saúde que assistem a mulher nessa fase do ciclo grávido-puerperal, esperam, desejam, induzem, monitoram e controlam essa dor. E as parturientes vivem-a.

Helman (1994) afirma que a pessoa com dor pode demonstrá-la verbal ou não verbalmente. Quando ela opta por fazê-lo, torna a experiência e a percepção privada da dor em um acontecimento público e social, a dor privada transforma-se em dor pública.

0 comportamento de dor, isto é, sua comunicação pela pessoa que a vivência, quando o faz para outras pessoas, é influenciado por fatores sociais, psicológicos e culturais. Portanto, varia de acordo com a cultura e a época. Isto porque a personalidade, o ambiente, a cultura, a religião, o gênero, entre outros aspectos, afetam

Recebido em 12/09/02 aceito em 19/07/02

Extraído da Tese de Doutorado "Da obtenção de informação ao esquecimento: a vivência da dor de parto em um hospital-escola", Escola de Enfermagem da Universidade de São Paulo, 1999.

* Enfermeira obstetra. Doutora em Enfermagem. Professor Doutor da Escola de Enfermagem da Universidade de São Paulo, atuando na área de enfermagem na saúde da mulher e enfermagem obstétrica. Escola de Enfermagem da Universidade de São Paulo. e-mail: miwa@ usp.br

** Obstetriz. Livre-docente. Professor Associado da Escola de Enfermagem da Universidade de São Paulo, atuando nas áreas de enfermagem na saúde da mulher e enfermagem obstétrica. Escola de Enfermagem da Universidade de São Paulo. e-mail: drgualda@ usp.br 
diretamente a percepção de dor e a resposta correspondente a ela (Crook, 1985; Bond, 1986; Ferreira, 1994; Thomas, 1997; Pereira e Zago, 1998; Guimarães, 1999; P imenta e Portinoi, 1999).

Em relação à dor de parto, esses aspectos também devem ser considerados, como é demonstrado por um trabalho transcultural do parto desenvolvido por J ordan (1993) nas culturas norte americana, sueca, holandesa e de Yucatan no México, onde a dor tem um papel de destaque para tornar o parto visível e caracterizá-lo como um acontecimento natural ou médico.

Dessa maneira, nesse estudo decidimos conhecer as crenças, os valores, o significado e os comportamentos relacionados à dor de parto por mulheres que as vivenciaram e receberam assistência durante o trabalho de parto em um hospital-escola, no qual o emprego de analgesia no trabalho de parto e a presença do acompanhante não são práticas rotineiras.

\section{METODOLOGIA}

\section{REFERENCIALTEÓRICO E METODOLÓGICO}

A opção pela pesquisa qualitativa baseia-se, em parte, na possibilidade de compreender valores culturais e nas representações de determinado grupo sobre temas específicos (Minayo,1994). E a sua importância para a Enfermagem deve-se ao fato de contribuir no desenvolvimento da própria profissão e do conhecimento, na exploração de alguns problemas sobre a assistência de enfermagem e na compreensão holística do homem, de acordo com Gualda; Merighi; O liveira (1995).

Para a condução deste estudo, utilizamos como referencial teórico a Antropologia Cultural. Segundo Bernardi (1974), este ramo da antropologia enfoca o significado e as estruturas da vida do homem como expressão de sua atividade mental. Este autor afirma que as manifestações desta atividade são expressões de escolhas determinadas que o homem faz para organizar a própria vida e que constituem a cultura; e acrescenta que nas suas escolhas, o homem é condicionado pelas suas características individuais, pelas relações que o ligam a outros indivíduos com os quais convivem e pelo ambiente em que vive.

A cultura é que distingue o homem de outros animais, ou seja, é capaz de criar e conservar a cultura. Ela é algo mais do que um conjunto de formas isoladas de comportamentos instintivo (Bernardi, 1974; Hoebel, 1982; Marconi; Presotto, 1992 ; Mello, 1995). Assim, Geert (1989) enfatiza que a cultura é uma ciência interpretativa na medida em que ela procura significado para o comportamento humano, que é considerado como ação simbólica passível de interpretação.

Para o procedimento metodológico, adotamos a Etnografia que busca a compreensão do fenômeno ou evento pesquisado, mas do ponto de vista nativo dos indivíduos que pertencem à cultura, onde o estudo se realiza (Spradley, 1979, 1980). Desta forma, o desenvolvimento do trabalho de campo é essencial neste método, em especial a observação participante. Assim, para a sua realização seguimos as fases preconizadas por Leininger (1991), em um continuum temporal que vai da observação à participação, conduzindo a reflexão.

\section{O PROCEDIMENTO METODOLÓGICO}

Os critérios para a seleção das informantes foram a vivência da dor de parto, independente do tipo de parto pelo qual se ultimou a gestação; ter recebido assistência durante o trabalho de parto e parto no hos pitalescola escolhido e a aceitação da mesma em participar do estudo, após o esclarecimento do objetivo da pesquisa e da garantia do seu anonimato, bem como de que o aceite ou a recusa não implicaria em prejuízo no atendimento atual ou futuro de sua pessoa ou familiares, e de seu filho na instituição. Totalizando sete mulheres que deram à luz no hospital no período de abril a dezembro de 1998, e que neste estudo são identificadas pelo seu respectivo signo do zodíaco.

A coleta de dados foi realizada após a aprovação do projeto de pesquisa ter sido aprovado pelo Comitê de Ética em Pesquisa da instituição, campo de estudo, por meio da observação participante e entrevistas com as 
mulheres em sua própria residência, em data e horário previamente agendados, no período de 20 a 57 dias após o parto. Cada mulher foi entrevistada mais de uma vez e no nosso primeiro encontro, a questão apresentada à mulher foi: "me fale como foi para você sentir a dor de parto". Nos encontros subseqüentes, utilizamos o emprego da entrevista semi-estruturada. 0 registro das informações obtidas na entrevista foi o uso de um gravador, com a ciência e o consentimento prévio da mulher.

Inicialmente, as entrevistas foram transcritas na íntegra. $\mathrm{Na}$ etapa seguinte, procedeu-se a leitura de cada entrevista repetidas vezes, analisando-as cuidadosamente no sentido de identificar os temas centrais abordados por cada informante em relação à dor de parto. Assim, obteve-se a saturação de informações que possibilitou a não inclusão de novas informantes, bem como o estabelecimento do limite de até três entrevistas com a mesma mulher.

G eer女 (1989) salienta que na pesquisa etnográfica, os textos são eles mesmos interpretações, na verdade, de segunda mão. 0 etnógrafo apresenta e descreve a cultura para aqueles que não a conhecem ou vivenciaram.

Em relação ao cenário cultural no caso específico do nascimento e parto, J ordan (1993) acrescenta que o conhecimento do local onde o parto ocorre em cada sociedade é importante e permite saber como este evento é definido, tanto pelas parturientes como pelas pessoas que as assistem. Estas pessoas compartilham de idéias similares quanto ao curso e à assistência no trabalho de parto e parto.

0 presente estudo foi desenvolvido na unidade de centro obstétrico de um hospital universitário, situado na cidade de São Paulo. A população atendida pela instituição é constituída, basicamente, de alunos, docentes e funcionários da universidade, da qual o hospital faz parte, além de pessoas que residem na área de abrangência para o qual o hospital é referência.

A equipe de atendimento à parturiente é constituída por enfermeiras obstetras, auxiliares e técnico de enfermagem, médicos obstetras, residente em obstetrícia e estudantes de cursos de graduação em Enfermagem e Medicina. A presença do acompanhante durante o trabalho de parto não é, ainda, uma prática rotineira.

0 processo de admissão da mulher na unidade é de responsabilidade da equipe médica e o acompanhamento da evolução do trabalho de parto e a assistência mais direta à parturiente, no setor de préparto, é realizado pela enfermeira obstetra, assim como, a execução do parto sem distócia na ausência de estagiários sob supervisão de um profissional.

0 emprego da analgesia no trabalho de parto não é freqüente. Desta forma, a enfermeira obstetra, para promover o conforto e bem-estar das parturientes em relação à dor de parto, indica intervenções não farmacológicas, principalmente o banho de chuveiro (Ochiai, 2000).

\section{RESULTADOS E DISCUSSÃO}

Este estudo explorou a vivência da dor de parto por mulheres que deram à luz em um hospital-escola, isto é, de um fenômeno inerente e exclusivo do processo de parturição, e os achados evidenciaram a necessidade das mulheres entrevistadas correlacionarem o tema da pesquisa com a fase anterior do ciclo grávido-puerperal, a gestação.

A experiência da dor de parto é influenciada por vivências e informações recebidas durante a gravidez, onde os familiares desempenham um papel importante, como elementos transmissores das informações sobre 0 tema, bem como, de acolhimento e tranquilizadores da gestante diante dos sentimentos gerados pela proximidade desta vivência.

E $m$ relação à dor de parto no período gestacional, neste estudo, foram identificados três domínios culturais:

1) a obtenção de informações sobre a dor de parto

2) os sentimentos vivenciados pela mulher em relação à dor de parto

3) a convivência com estes sentimentos. 


\section{A OBTENÇÃO DE INFORMAÇÕES SOBRE A DOR DE PARTO}

$\mathrm{Na}$ gestação, as mulheres recebem maior carga de informações a respeito da dor de parto. Elas ouvem comentários:

“... durante a minha gravidez, muita gente falava como foi o parto dela. Coisas que ninguém contava antes, né? Antes de eu ficar grávida, né?" (Virgem)

"As pessoas me assustaram na gravidez, falam que o parto é bicho de sete cabeça porque é a pior dor do mundo. Quando eu estava grávida, quando elas já sabiam que eu estava grávida. Aí começavam a falar..." (Touro)

As mulheres ressaltam, ainda, que o seu papel no processo de obtenção de dados sobre a dor de parto, geralmente, é passivo. A apresentação das informações lhes é imposta e o agente destas são invariavelmente de outras mulheres com laços de parentesco ou amizade e que já tinham vivenciado a dor de parto, salientando 0 aspecto negativo desta experiência.

“... as pessoas falavam muito. As pessoas assim, a mãe da gente, a irmã, as tias, todas as mulheres da família! ... Eu, nem precisa perguntar. Todo mundo já ia contando. Contavam um montão de coisa, mesmo que eu num quisesse ouvir." (Aquário)

“... as pessoas já tinham falado pra mim, na primeira gravidez, né? Que era uma dor horrível. E ram as primas, as tias. Que nessa época eu morei em Brasília. Então eu tava grávida, não tinha mãe, minhas irmãs. Eu não tinha elas perto de mim. Aí então, eu só tinha parentes assim: primas, tias. Então as que já tinham filho falavam que era muito forte, que a gente não suportava, que parecia a dor da morte..." (Capricórnio)

\section{OS SENTIMENTOS VIVENCIADOS PELA MULHER EM RELAÇÃO À DOR DE PARTO}

0 teor das informações sobre a dor de parto recebidas pelas gestantes e a forma que elas são transmitidas geram na mulher diversos sentimentos, tais como a dúvida, a descrença/ incredulidade, a curiosidade, o medo e a resignação.

Estes sentimentos relacionados à dor de parto identificados pelas gestantes e citados acima, alteram-se constantemente, um substituindo o outro de forma dinâmica, sempre na dependência das informações obtidas e/ ou vivenciadas pelas mulheres no evolver da gravidez. Há a alternância de sentimentos, no entanto, com maior freqüência a dor de parto é caracterizada como sendo extremamente negativa, por conseguinte, o medo predomina entre todos os sentimentos.

“... eu tinha medo da dor porque falavam que ela é forte, muito forte. Mas aí eu tinha medo de fazer escândalo. Minhas irmãs falavam que quando faz escândalo, o enfermeiro deixa lá. Só vai de vez em quando, tal. Que nem muita gente fala que se você faz escândalo, eles falam: é, na hora de fazer, ninguém faz escândalo tal, essas coisas. Elas comentavam que a dor de parto era terrível, tudo! Que era uma monstruosidade! Aí eu ficava com medo, né? Medo, né? Porque elas falavam aquilo pra mim." (Aquário)

“... a Lúcia, minha prima. Ela me colocou uma porção de medo." (Capricórnio)

Assim, no transcurso do período gestacional, em geral, a mulher tem contato com várias fontes de informações sobre a dor de parto e o conteúdo desta informação. Entre estas fontes, as mulheres citaram a literatura dirigida particularmente às grávidas; a mídia, em especial, a televisão e profissionais de saúde. Entretanto, as mulheres de suas relações familiares e de amizade continuam à desempenhar papel fundamental na geração 
destes sentimentos. 0 que nos chama à atenção, que este papel demonstra ser mais relevante que as próprias enfermeiras, gestantes, médicos, auxiliares de enfermagem, entre outros, uma vez que todas as mulheres entrevistadas realizaram acompanhamento pré-natal.

\section{A CONVIVÊNCIA COM OS SENTIMENTOS EM RELAÇÃO À DOR DE PARTO DURANTE A GRAVIDEZ}

As mesmas mulheres das relações familiares (primas, irmãs, cunhadas, mães) ou de amizade, que transmitem as informações negativas em relação à dor de parto com base em suas próprias vivências, são simultaneamente as pessoas com as quais as gestantes podiam buscar apoio. Este consistia na técnica da escuta da verbalização destes sentimentos.

"E tinha medo, aí eu fui falar com minha outra irmã, né. Ela já tinha tido dois filhos. Tudo normal, né. E la disse que dói mesmo, que dá medo mesmo. Medo até de morre. Eu falei pra ela que eu tava também com medo. Ela tava fazendo a janta. Fiquei lá, né. Falando pra ela e ela lá fazendo a comida pras crianças dela." (Virgem)

No caso de Touro, o próprio marido foi o personagem que desempenhou este papel:

“Aí eu chegava e contava tudo pra ele. Aí ele ficava: não é assim, você não pode ficar assim. Você tem que relaxar, cada mulher tem um corpo diferente, não? Então, o sofrimento é menos, não vai ser que nem da minha irmã."

\section{CONSIDERAÇÕES}

A dor de parto, apesar de se constituir em um fenômeno próprio do parto, é um tema que preocupa a mulher desde o período gestacional. Apesar do avanço tecnológico, inclusive legal, no sentido da possibilidade do alívio da dor de parto por meio da analgesia, bem como do atual conhecimento científico de formas não farmacológicas do alívio deste tipo de sensação dolorosa; acrescido da realização de acompanhamento pré-natal pela maioria das mulheres da população dos centros urbanos e as políticas públicas de incentivo a sua realização, este estudo evidenciou a ineficácia da assistência prestada à mulher durante a gestação em relação a abordagem do tema.

A falta de oportunidade durante os nove meses de gestação para a mulher poder obter informações baseadas em evidências científicas, mesmo participando de grupo de gestantes; discutir e compartilhar com os profissionais de saúde, inclusive da Enfermagem, as dúvidas, a desinformação, as fantasias, as experiências, entre outros aspectos quanto à dor de parto, obriga-nos à re-pensar e modificar nossa prática profissional quanto à educação para a saúde, considerando-se que o parto normal é um evento natural e fisiológico. Sem anular ou desvalorizar as crenças e valores em relação à dor de parto, que é transmitida pelas outras mulheres com as quais a gestante convive devido à laços de parentesco ou de amizade.

0 presente estudo demonstra que os familiares das gestantes preenchem o vazio deixado pelos profissionais de saúde em relação à dor de parto na assistência pré-natal.

ABSTRACT: This ethinographic study aimed to understand the labor pain experienced by the women who gave birth to a child in a school hospital in São Paulo city, where the usage of peridural is not very frequently applied and the presence of a companion during the labor is also restrict. It was used the cultural antropology as reference. Although the labor pain is a characteristic event of the labor, this study showed that the woman is worried about this future and next experience during her pregnancy. The prenatal assistance that is given to these women has been failing in this aspect, which makes even more important the participation of these women's relatives in their expectation.

KEY WORDS: Pain; Delivey; Family. 
RESUMEN: Este estudio etnográfico tuvo como objetivo comprehender la vivencia del dolor de parto de mujeres que dieron a luz en un hospital escuela de la ciudad de São Paulo, donde con mucha frecuencia no se emplea la analgesia y la presencia del acompañante es restringida.Se adoptó como referencial teórico la Antropologia cultural. El dolor de parto, a pesar de ser un evento inherente a él, en este estudio fué evidenciado como una preocupación sentida por la mujer durante toda la gestación, anticipándose al inevitable dolor del parto. La asistencia prenatal proporcionada ha mostrado fallas en relación a este aspecto, lo que hace resaltar la importancia que tiene que los familiares de estas mujeres compartan esta expectativa.

PALABRAS CLAVE: Dolor; Parto; Familia.

\section{REFERÊNCIAS}

1 BERNARDI, B. Introdução aos estudos etno-antropológicos. Lisboa: E dições 70, 1974.

2 BOND, M. R. Dor: natureza, análise e tratamento. 2.ed. Rio de J aneiro: Colina, 1986.

3 CROOK, J. Women in pain. In: COOP, L. A. (Ed.). Perspectives on pain. New York: Churchill Livingstone, 1985. cap.8, p. 113-137.

4 FERREIRA, J 0 corpo sígnico. In: ALVES, P. C.; MINAYO, M. C. de S. (O rg.). Saúde e doença: um olhar antropológico. Rio de J aneiro: FIOCRUZ, 1994. cap. 8, p. 101-112.

5 GEERTZ, C. A interpretação das culturas. Rio de J aneiro: LTC, 1989.

6 GUALDA, D. M. R.; MERIG HI, M. A. B.; OLIVEIRA, S. M. J. Abordagens qualitativas: sua contribuição para a enfermagem. Rev. Esc. Enf. USP, São Paulo, v. 29, n.3, p.297-309, 1995.

7 GUIMARÃES, S. S. Introdução ao estudo da dor. In: CAR VALHO, M. M. M. J . de. Dor: um estudo multidisciplinar. São Paulo: Summus, 1999. cap.2, p.13-30.

8 HELMAN, C.G. Cultura, saúde e doença. 2.ed. Porto Alegre: Artes Médicas, 1994.

9 HOE BEL, E. A. A natureza da cultura. In: SHAPIRO, H. L. Homem, cultura e sociedade. 3.ed. São Paulo: Martins Fontes, 1982. cap.7, p.219-233.

10 J ORDAN, B. Birth in four cultures: a crosscultural invesgation of childbirth in Yucatan, Holland, Sweden and the United States. Chicago: Waveland P ress, 1993. cap.3, p.45-90.

11 LEIN INGER, M. M. Culture care diversity and university: a theory of nursing. New York: National League for Nursing P ress, 1991. cap.2, p.73-117.

12 MARCONI, M. deA.; PRESOTTO, Z. M. N. Antropologia: uma introdução. 3.ed. São Paulo: Atlas, 1992.

13 MELLO, L. G. Antropologia cultural: iniciação, teorria e temas. 6.ed. Petrópolis: Vozes, 1995.

14 MINAYO, M. C. de S. O desafio do conhecimento: pesquisa qualitativa em saúde. 3.ed. São Paulo: Hucitec, 1994. cap.3.

15 OCHIAI, A M. O banho de chuveiro como medida de alívio da dor no trabalho de parto. São Paulo, 2000. 105p. Dissertação (Mestrado) - Escola de Enfermagem, Universidade de São Paulo.

16 PEREIRA, A. P. S.; ZAGO, M. M. F. As influências culturais na dor do paciente cirúrgico. Rev. Esc. Enf. USP, São Paulo, v.32, n.2, p.144-152, 1998.

17 PIMENTA, C.A. M.; PORTINOI, A.G. Dor e cultura. In: CARVALHO, M. M. M. J . Dor: um estudo multidisciplinar. São Paulo: Summus, 1999. cap.8, p.159-173.

18 SPRADLEY, J. P. The etnographic interview. New York: Holt, Rinehart \& Winston, 1979.

19 SPRADLEY, J.P. Participant observation. New York: Holt, R inehart \& W inston, 1980.

20 THOMAS, V. N. Pain: its nature and management. London: Baillière Thindall, 1997. cap.2, p.20-34. 